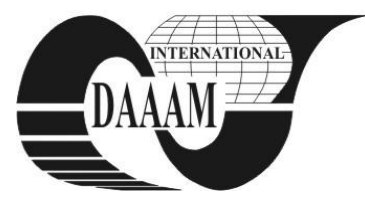

Annals of DAAAM for 2011 \& Proceedings of the 22nd International DAAAM Symposium, Volume 22, No. 1, ISSN 1726-9679 ISBN 978-3-901509-83-4, Editor B. Katalinic, Published by DAAAM International, Vienna, Austria, EU, 2011 Make Harmony between Technology and Nature, and Your Mind will Fly Free as a Bird Annals \& Proceedings of DAAAM International 2011

\title{
OPTIMIZATION OF DRYING PROCESS PLANKS BEECH BY ARTIFICIAL WAY
}

\author{
HODZIC, A[tif]; DZANIC, A[mel] \& NEZIREVIC, E[krem]
}

\begin{abstract}
The experiment was conducted on an actual model, at artificial drying of $32 \mathrm{~mm}$ thick beech planks. The drying process was conducted in the conventional drier and used to create a mathematical model of the influence of the drying parameters (temperature, relative humidity and air velocity) on the duration of the artificial drying process. Based on the obtained mathematical model Kollmann's empirical formula for calculating the drying time is improved and optimization of parameters of the drying process was conducted. The paper used the method of non-linear programming with constraints and direct search, given that the objective function is not linear but quadratic with iterations between the variables. The optimized results were analyzed with data from the drying practice to get the confirmation of the hypothesis, since resulting output obtained with improved formula is far more approximate to actual values of the drying process.

Key words: temperature, relative humidity, air velocity, mathematical model, optimization, drying time
\end{abstract}

\section{INTRODUCTION}

Duration of drying process is the time needed for the wood to dry from initial to the final content of humidity in the process of natural or artificial wood drying. It depends on several variable factors such as: volume weight, structure, thickness and humidity of the wood, temperature, relative humidity and air velocity in the chamber, as well as the type and operation method of the dryer (Kolin, 2000). The influence of volume weight, structure, thickness and humidity of wood on the duration of the drying process was mathematically determined, whereas the influence of the type and operation method of the dryer can not be significantly changed, and as such cannot be considered as a constant value. Optimal sizes of air flow through stacked planks, and the significance of the influence of the relative humidity in the chamber, with the purpose of shortening the drying process, are still not significantly explored. Searching of scientific literature and manuals on artificial drying did not yield any results in terms of finding mathematical patterns of the influence of relative humidity and air velocity in the chamber on the drying rate, i.e. total duration of the drying process (Hodzic, 2010).

Optimization can be understood as a process of defining solutions for given initial conditions from the set of possible solutions, with no restrictions on the choice of object optimization. The process of defining objectives, variables and possible limits for a given problem is named the modeling process. Forming a good model is the first step, and very commonly the most important step, in the optimization process. After a model is defined, optimization procedures can be used so as to find solution to the problem. Optimization procedure can be mathematically expressed as finding a minimum or maximum value of objective function. Generally, the objective function is a scalar function $F$ with one or more parameters $\mathrm{x}_{\mathrm{i}}$, depending on how many variables are considered during the model optimization procedure.

\section{EXPERIMENTAL RESEARCH ON THE ACTUAL MODEL}

Beech lumber was dried in the conventional drier of $20 \mathrm{~m}^{3}$ capacity, which is equipped with an automatic device for the drying process maintenance, supported by the computer. The dryer is equipped with functional elements for the maintenance and measurement of the examined thermodynamic parameters: temperature $(t)$, relative humidity $(\varphi)$ and air velocity $(w)$. Those parameters were recorded on regular basis and stored in the device memory (Hodzic, 2010).

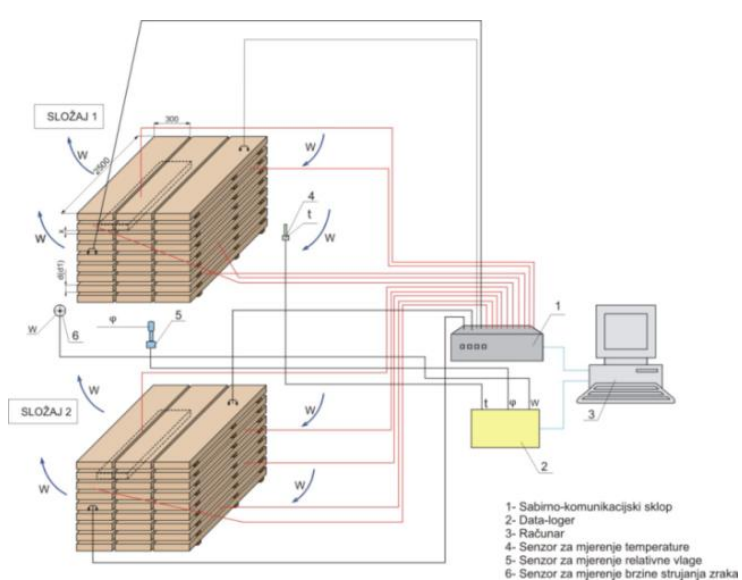

Figure 1 Schema of the experimental device

For the measurement and comparative analysis of the actual size of the examined factors in the chamber mini data logger with 4 external channels Hobo H8-ext was used, which, assisted by the temperature sensor TMC-20HD, hygro adapter PCE-HA-702 and anemometer adapter PCE-AM-402, was measuring temperature, relative humidity and air velocity in the chamber. The device is equipped with software BCP4.3-DL for logger parametring, reading data, graphic display, and the ability to compare multiple parameters in one graphics (Hodzic, 2010). The measurements were taken every hour during the drying process. The sensors were placed in the chamber, and through a flexible cable connected to the data logger that was placed outside the dryer. Schema of the experimental device is shown in Figure 1.

The objective of the experimental research is to investigate factors influencing the drying, such as temperature, relative humidity and air velocity, in the chamber during artificial drying of $32 \mathrm{~mm}$ thick beech lumber, and the analysis of the experimental data in terms of achieving higher drying rate, i.e. shorter drying process duration, without jeopardizing the quality of dried materials and reducing overall production costs. The following factors of the drying process were investigated on five levels:

- $\quad$ temperature $\mathrm{T}=32,35,40,45$ and $48{ }^{\circ} \mathrm{C}$

- relative humidity $\varphi=42,45,50,55$ and $58 \%$

- $\quad$ air velocity $\mathrm{w}=1.1,1.3,1.6,1.9$ and $2.1 \mathrm{~m} / \mathrm{s}$ 
The experiment used rotatable plan, which is often used in modeling and adaptive control of processes with multiple variables. This plan contains a basic part of the plan $2^{\mathrm{k}}$, symmetrically placed point $\mathrm{n}_{\alpha}$ around the center point of the plan and repetitive point $\mathrm{n}_{0}$ in the center of the plan. In this case the $k=3$ (variables: $\mathrm{t}, \varphi, \mathrm{w}$ ), $\mathrm{n}_{0}=6$ and $\mathrm{n}_{\alpha}=6,\left(n_{\alpha}=2 k\right)$, with the total number of experiment: $N=8+$ $6+6=20$. Table 1 presents the analytical results of the experiment on actual model.

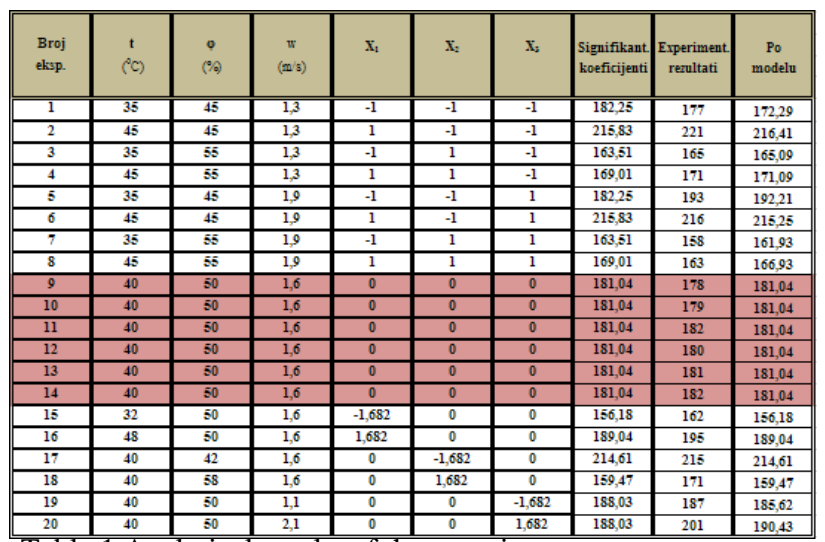

Table 1 Analytical results of the experiment

\section{Mathematical modeling}

The main goal of the mathematical modeling is to determine the validity of the relationship between input and output parameters, of which the input parameters define the terms of the process, whereas the output parameters serve as results of the modeled process (Jurković, 1999). Student's test was used to assess the adequacy of the mathematical model. Table 2 presents the analysis of the adequacy of the mathematical model.

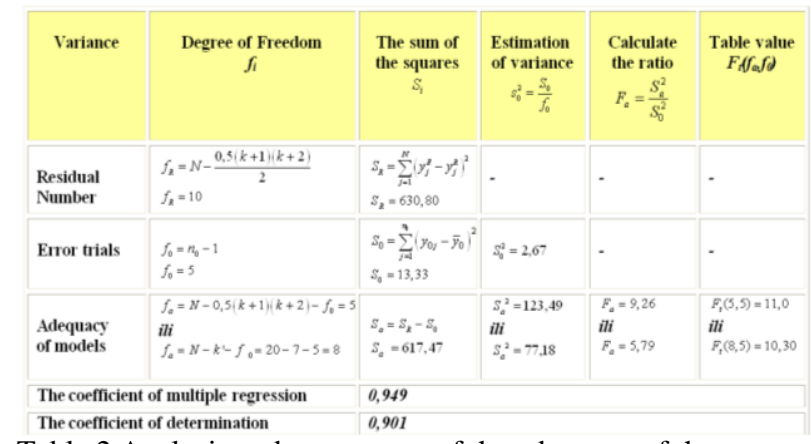

Table 2 Analysis and assessment of the adequacy of the mathematical models

After calculating the regression coefficients and assessing their significance, we have obtained the initial model in coded form:

$y=181,04+9,77 X_{1}-16,39 X_{2}+1,43 X_{3}-2,98 X_{1}^{2}+2,12 X_{2}^{2}+$ $2,47 X_{3}^{2}-7,02 X_{1} X_{2}-2,76 X_{1} X_{3}-3,26 X_{2} X_{3}+2,51 X_{1} X_{2} X_{3}$

The final form of the mathematical model of the drying parameters' influence on the duration of the process is:

$z_{3}=(-203,37-0,28 t \varphi)-t(0,12 t-25,53)+\varphi(0,08 \varphi-0,53)+$ $w(27,39 w-87,68)$

\section{OPTIMIZATION OF DRYING PARAMETERS}

The paper used the method of non-linear programming with constrains and direct search, given that the objective function is not linear but quadratic with iterations between the variables. Decoded mathematical model is assumed objective function.

$$
F_{\text {cilja }}=y\left(x_{1}, x_{2}, x_{3}\right)=z_{3}(t, \varphi, w)
$$

Condition was set for the objective function:

$$
F_{\text {cilja }}=z_{3}(t, \varphi, w) \rightarrow \min
$$

And the following constraints:

$32,0 \leq t \leq 48,0$

$42,0 \leq \varphi \leq 58,0$

$1,10 \leq w \leq 2,10$

The programming language $\mathrm{C}++$ was used to develop the application for searching a minimum of the function objective with the following step:

- $\quad$ for $\mathrm{t}: \mathrm{t}=\mathrm{t}+0,1$;

- for $\varphi: \varphi=\varphi+0,1$;

- for $\mathrm{w}: \mathrm{w}=\mathrm{w}+0,01$.

Constraints were given in the interval endpoints of the modeling parameters: $t, \varphi$ and $w$. After searching a few thousand combinations of these three parameters, values were obtained of the minimum objective and parameters $t, \varphi$ and $w$ function, at points of minimum objective function (Hodzic, 2010).:

$$
F_{\text {cilja }}=z_{3}(t, \varphi, w)=134,282=F_{\min }
$$

i.e.:

$t=47,9998{ }^{\circ} \mathrm{C}, \varphi=57,9998 \%$ and $w=1,60 \mathrm{~m} / \mathrm{s}$

\section{CONCLUSION}

Based on the experiment conducted in the actual environment we have obtained the mathematical model of the influence of temperature, humidity and air velocity during the drying process. The model was optimized and obtained the optimal values of the drying parameters on which the calculated minimum duration process of drying was modeled. Based on the analytical expressions for calculating the drying time by Kollmann, we have created mathematical models for parameters of drying process, and as result we have modified Kollmann's expression:

$$
Z_{3}=z_{(t, \varphi, w)} \cdot\left(\ln u_{p}-\ln u_{k}\right) \cdot\left(\frac{d}{25}\right)^{1,25}
$$

where:

$$
\begin{aligned}
& Z_{(t, \varphi, w)}=(-203,37-0,28 t \varphi)-t(0,12 t-25,53)+\varphi(0,08 \varphi-0,53) \\
& +w(27,39 w-87,68)
\end{aligned}
$$

Resulting expression has significantly modified the results of the approximate drying time of the beech planks in relation to Kollmann's expression.

\section{REFERENCES}

Hodžić A.: ,Matematičko modeliranje i optimizacija procesa sušenja u procesu obrade drveta", Doctoral dissertation, Faculty of Technical Engineering, Bihać, 2010

Jurković, M.: ,Matematičko modeliranje inženjerskih procesa $i$ sistema“, Faculty of Mechanical Engineering, Bihać, 1999

Kolin I. B.: "Hidrotermička obrada drveta ", Jugoslavija publik, 86-7121-070-7, Beograd 2000

Takači A. et al.: „Matematičko modeliranje“, Faculty of Science, Novi Sad, 2006

Vukelja D.; Mišković A.: „Inženjerske metode optimizacije“, Građevinska knjiga, Beograd, 1985.opt 